\title{
Cognitive Neural Mechanism in Second Language Learning
}

\author{
Yajun Xie* \\ ${ }^{1}$ School of Foreign Languages, Hunan University of Commerce, China
}

Received: 阱 July 6, 2018; Published: 眥 July 13, 2018

*Corresponding author: Yajun Xie, School of Foreign Languages, Hunan University of Commerce, Changsha Hunan 410205, China

Abbreviations: FMRI: Functional Magnetic Resonance Imaging; ERP: Event-Related Potential; TDCS: Transcranial Direct Current Stimulation

\section{Mini review}

This paper sums up the existing studies on the neural features of second language (L2) from the perspective of learning experience. After combing and analyzing the cognitive neural mechanism of L2 learning, it is concluded that: [1] L2 learners rely on the neural network of the native language (L1) to learn and process L2; [2] The L2 proficiency is positively correlated with the use of L1 neural network in the processing of L2; [3] L2 is learned through its interaction with L1. In future, modern cognitive neuroscience techniques like functional magnetic resonance imaging (fMRI), event-related potential (ERP) and transcranial direct current stimulation (tDCS) should be applied more frequently to discuss the cognitive neural mechanism of L2 learning in natural and lab environments. This research sheds new light on the promotion of L2 learning. Second language (L2) refers to a language that is not the native language (L1) of the speaker, but that is used in the locale of that person.

The number of L2 learners is increasing day by day across the world. The European Commission once conducted a survey on L2 learning, revealing that $56 \%$ of Europeans can communicate in two languages. China also boasts a huge number of L2 learners. Against this backdrop, it is very meaningful to promote the research into L2 learning. One of the research focuses lies in cognitive neural mechanism. A clear understanding of this mechanism helps enrich the existing theories on language processing and guide the design of brain-based learning methods and software for L2 learning. Many scholars have explored the cognitive neural mechanism of L2 learning using functional magnetic resonance imaging (fMRI), which is a typical modern brain imaging technology. In light of the above, this paper sums up the existing studies on the neural features of $\mathrm{L} 2$ from the perspective of learning experience, aiming to shed new light on future research.

In the research of L2 learning, a basic problem is the acquisition of L2 neural features through learning. In recent years, this problem has been investigated repeatedly using modern brain imaging technology. Some scholars disclosed the effect of learning experience on L2 neural features through comparison between proficient bilinguals [2-4]. Their research reveals the positive correlation between that the cognitive efforts in L2 processing and the proficiency of the bilinguals. For instance, lower-proficiency bilinguals are more active in the frontal cortex and parietal cortex than high-proficiency ones, because they have to pay more cognitive efforts to complete vocabulary reading tasks [5]. It is also found that low-proficiency bilinguals are more activated in the posterior visual cortex during the processing of L2 vocabulary [6].

In addition, the involvement of L1 neural network in L2 processing and learning depends on the age of L2 acquisition. Kim et al. contrasted the neural mechanisms of early bilinguals (those who start to learn L2 in infancy) and late bilinguals (those who start to learn L2 after the age of 10). The results show that the L1 and L2 of late bilinguals are isolated from the Broca's area, while those of early bilinguals share similar neural features in that area [7]. Some other scholars directly examined the acquisition of L2 neural features through learning, using the language learning paradigm in the lab environment [8-12]. In this way, they managed to observe the variation in L2 neural features with the learning experience in the short term and separate the cognitive neural mechanism of learning from the different aspects of theL2.

In terms of auditory and verbal learning, Wang et al. investigated the cognitive neural mechanism of native speakers for the learning of and differentiation between Chinese tones [13] and learned that the tone processing activates the brain areas related to auditory processing, including Broca, Wernicke, auditory cortex and accessory motor areas. Wong et al. examined the cognitive neural mechanism of native speakers learning English pseudo tones with Chinese tones [14] and concluded that those with higher learning scores are more active in the speech processing brain (left posterior temporal gyrus), while those with lower scores are more active in the right lateral temporal gyrus and the right lower frontal gyrus. Besides tone learning, the scholars also studied the cognitive neural mechanism of L2 phoneme learning. Callan et al. probed into the 
brain mechanism of Japanese native speakers in learning English phonemes / $\mathrm{r} /$ and /l/ and drew the following conclusions: the native speakers' recognition performance improved significantly after repeated perceptual discrimination training, and the training boosted the activation of bilateral superior temporal gyrus, subfrontal gyrus and subcortical tissue [15].

Golestani et al. also found similar results in the research into native English speakers in India concerning dental and retroflex [16]. In terms of reading, much research has been done on the glyph, phonetics and semantic learning of L2. Hashimoto et al. explored the brain mechanism of native Japanese speakers learning Korean phonology [17], pointing out that language learning conditions surpasses the nonverbal learning conditions in the activation of the left posterior inferior temporal gyrus and parietal occipital region. Lee et al. also studied the brain mechanism of native Japanese speakers learning to read Korean words. The study shows that, before learning Korean, reading Japanese words activated more left angular gyrus than reading Korean words; after learning, there was no difference in the activation of the left corner. The results demonstrate the importance of the left corner gyrus in L2 vocabulary learning [18].

Further research on reading shows that the neural mechanism differs with the aspect of L2 vocabulary. Based on the phased artificial language training paradigm, Xue et al. looked into the cognitive neural mechanism of the L2 font, speech and semantic learning [8], and observed that spindle gyrus on both sides were less activated due to glyph learning but enhanced after speech and semantic learning. These results show that the L2 learning experience in grapheme, voice and semantics plays different roles in the activity of spindle regions in critical brain regions. In addition to the different aspects of vocabulary, it is also found that the neural mechanism differed with the learning of different word systems in depth of orthography. Using the artificial language training paradigm, Mei et al. trained two groups of matched native speakers to learn the same artificial language in alphabetic script and graphic text, respectively. It is learned that phonetic alphabet learning activated the upper left margin of the left margin, and the graphic and literal learning activated the right orbitofrontal cortex and the ventral temporal gyrus.

The results provide evidence of brain science for dual routes model [19]. A variety of modern brain imaging techniques and experimental paradigms have been adopted to study the cognitive neural mechanism of L2 learning, and the interaction between L1 processing and L2 learning from the angles of group averaging and individual differences, leading to many important conclusions. In summary, bilingual research and language learning in the lab environment have greatly deepened the understanding of the cognitive neural mechanism of L2 learning. The bilingual studies agree that, with the improvement of L2 proficiency, the L2 shares more and more neural features with the L1; of course, the similarity is regulated by the age of L2 acquisition. In addition, the studies on language learning in the lab environment reveal that L2 learners rely on the L1 neural network to learn L2. In future, modern cognitive neuroscience techniques like functional magnetic resonance imaging (fMRI), event-related potential (ERP) and transcranial direct current stimulation (tDCS) should be applied more frequently to discuss the cognitive neural mechanism of L2 learning in natural and lab environments.

\section{Acknowledgement}

This work was supported by a grant from Social Science Foundation of Hunan Province "Research on the Implicit Cognition Mechanism of Second Language Acquisition" (No. 15YBA241)

\section{References}

1. Blom E, Küntay A C, Messer M, Josje V, Paul L et al. (2014) The benefits of being bilingual: working memory in bilingual Turkish-Dutch children. J Exp Child Psychol 128: 105-119.

2. Chee M W, Tan E W, Thiel T (1999) Mandarin and English single word processing studied with functional magnetic resonance imaging. Journal of Neuroscience 19(8): 3050-3056.

3. Luk G, Green D W, Abutalebi J, Cheryl G (2012) Cognitive control for language switching in bilinguals: A quantitative meta-analysis of functional neuroimaging studies. Language \& Cognitive Processes 27(10): 1479-1488.

4. Chee M W, Soon C S, Lee H L (2003) Common and segregated neuronal networks for different languages revealed using functional magnetic resonance adaptation. J Cogn Neurosci 15(1): 85-97.

5. Stein M, Federspiel A, Koenig T, Miranka W, Christoph L, et al. (2009) Reduced frontal activation with increasing $2^{\text {nd }}$ language proficiency. Neuropsychologia 47(13): 2712-2720.

6. Leonard M K, Torres C, Travis K E, Brown TT, Hagler DJ, et al. (2011) Language proficiency modulates the recruitment of non-classical language areas in bilinguals. Plos One 6(3): e18240.

7. Kim K H, Relkin N R, Lee K M, Joy H (1997) Distinct cortical areas associated with native and second languages. American Journal of Ophthalmology 124(6): 171-174.

8. Song Y, Yong B, Hu S, Y Luo, Jia Liu, et al. (2010) Short-term language experience shapes the plasticity of the visual word form area. Brain Research 1316(2): 83-91.

9. Mei L, Xue G, Lu Z L, He Q Wei M, (2015) et al. Native language experience shapes neural basis of addressed and assembled phonologies. Neuroimage 114: 38-48.

10. Mei L, Xue G, Lu Z L, Q He, M Zhang, et al. (2014) Artificial language training reveals the neural substrates underlying addressed and assembled phonologies. Plos One 9(3): e93548.

11. Xue G, Chen C, Jin Z, Dong Q (2006) Language experience shapes fusiform activation when processing a logographic artificial language: An fMRI training study. Neuroimage 31(3): 1315-1326.

12. Gao Q Wang J, Yu C, Chen H (2015) Effect of handedness on brain activity patterns and effective connectivity network during the semantic task of Chinese characters. Sci Rep 5: 18262.

13. Wang Y, Sereno J, Jongman A, Hirsch J (2003) fMRI Evidence for Cortical Modification during Learning of Mandarin Lexical Tone[J]. Cognitive Neuroscience Journal 15(7): 1019-1027.

14. Wong P C, Perrachione T K, Parrish T B (2010) Neural characteristics of successful and less successful speech and word learning in adults. Human Brain Mapping 28(10): 995-1006.

15. Callan D E, Tajima K, Callan A M, Kubo R, Masaki S, et al. (2003) Learninginduced neural plasticity associated with improved identification performance after training of a difficult second-language phonetic contrast. Neuroimage 19(1): 113-124.

16. Golestani N, Zatorre R J (2004) Learning new sounds of speech: reallocation of neural substrates. Neuroimage 21(2): 494-506. 
17. Hashimoto R, Sakai K L (2004) Learning letters in adulthood: direct visualization of cortical plasticity for forming a new link between orthography and phonology. Neuron 42(2): 311-322.

18. Lee H S, Fujii T, Okuda J, Tsukira T, Umetsu A, et al. (2003) Changes in brain activation patterns associated with learning of Korean words by Japanese: an fMRI study. Neuroimage 20(1): 1-11.

ISSN: 2574-1241

DOI: 10.26717/BJSTR.2018.06.001405

Yajun Xie. Biomed J Sci \& Tech Res

(C) This work is licensed under Creative

Submission Link: https://biomedres.us/submit-manuscript.php
19. Coltheart M, Rastle K, Perry C (2001) DRC: a dual route cascaded model of visual word recognition and reading aloud. Psychological Review 108(1): 204-256.

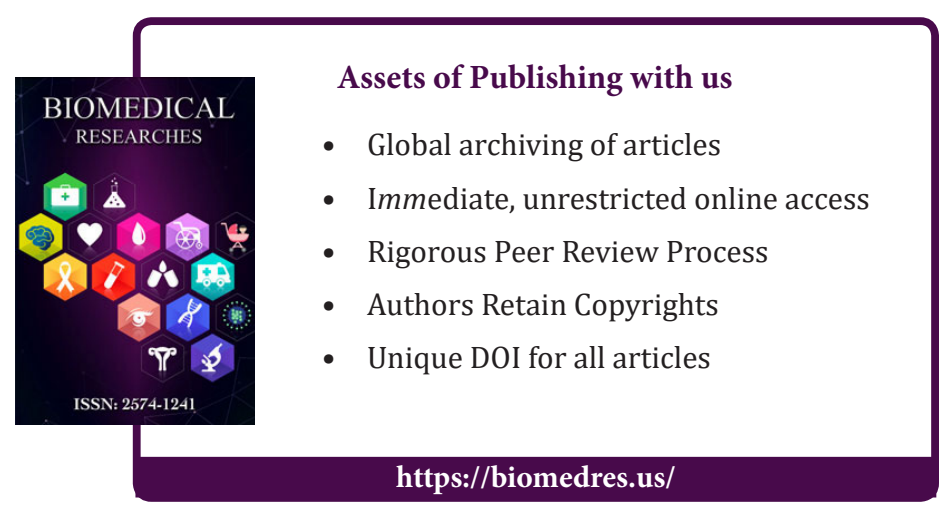

Cite this article: Yajun Xie. Cognitive Neural Mechanism in Second Language Learning. Biomed J Sci\&Tech Res 6(5)- 2018. BJSTR. MS.ID.001405. 